\title{
Subsistemas, Sectores y Estratos Sociales en la Historia Reciente de Iberoamérica
}

\author{
Francisco Lizcano Fernández \\ Facultad de Humanidades-UAEM
}

\begin{abstract}
Resumen: Fundamentalmente, este texto propone una representación de la estructura social prevaleciente en Iberoamérica durante la segunda mitad del siglo XX en donde se entrelazan tres tipos de componentes: estrato, sector, compuesto por unidades productivas similares y por uno o más estratos, y subsistema, integrado por sectores afines. De acuerdo con tal planteamiento, en las sociedades iberoamericanas actuales se distinguen tres subsistemas: el tradicional, el moderno y el informal. El primero aglutina tres sectores rurales: comunal, latifundista y campesino; el segundo, uno rural, capitalista, y dos urbanos: estatal y capitalista; el subsistema informal, por último, queda integrado únicamente por el sector urbano no estructurado.
\end{abstract}

Abstract: Basically, this text proposes a representation of the prevalent social structure in Iberoamerica during the second half of the XX century, where three types of components are intertwined: stratum, sector, compounded by productive similar units and for one or more strata, and subsystem, integrated by adjacent sectors. In accordance with such approach, in current iberoamerican societies three subsystems are distinguished: the traditional, the modern and the informal. The first agglutinates three rural sectors: communal, latifundist and peasant; the second, one rural, capitalist, and two urban: state and capitalist; the informal subsystem, lastly, is integrated only for the urban sector not structured.

\section{T a mayoría de quienes han considerado que para una mejor comprensión de las sociedades iberoamericanas en las últimas décadas era conveniente otorgar un papel central a su común estructura social, ${ }^{1}$ en lo fundamental han integrado sus respectivas interpretaciones de tal estructura con un sólo tipo de componente. El}

1 En las sociedades estratificadas, como las que ahora nos ocupan, el concepto de estructura social alude a las diferencias sociales más significativas, aquellas que condicionan profundamente la existencia global de personas y grupos sociales, pues ponen de manifiesto la desigual distribución de recursos materiales, el poder y el prestigio, aspectos que, además de su gran significación intrínseca, influyen directamente en otras dimensiones sociales básicas, como pueden ser la ideología, el comportamiento político, la salud y la educación. Por tanto, todo modelo de estructura 
procedimiento más usual ha sido dividirla en clases o estratos sociales, siguiendo las enseñanzas de Carlos Marx y Max Weber. ${ }^{2}$ Así han procedido, por ejemplo, los marxistas de las tendencias más diversas y los estructuralistas vinculados a la Comisión Económica para América Latina y el Caribe (CEPAL). ${ }^{3}$ Más recientemente, la Organización Internacional del Trabajo (OIT), en especial a través del ya desaparecido Programa Regional del Empleo para América Latina y el Caribe (PREALC), viene dividiendo la estructura social iberoamericana en cuatro sectores principales: dos agrícolas moderno y tradicional y dos urbanos: formal e informal.

Bajo la suposición de que ello permite una mejor comprensión de la heterogénea estructura social iberoamericana en la segunda mitad del siglo XX, quizá también en relación con periodos anteriores, en estas páginas se ofrece una propuesta provisional al respecto, en donde se

social debe delimitar sus componentes fundamentales y clasificarlos jerárquicamente de acuerdo con los principales tipos de desigualdad, así como señalar las relaciones duraderas, ordenadas y tipificadas existentes entre dichos elementos.

2 Numerosas y profundas, pero tienen en común, entre otras cuestiones, haberse constituido en fundamentos sólidos, los principales según ciertos autores, de los distintos enfoques desarrollados en las últimas décadas respecto a la estratificación social (Giddens, 1991: 241; Littlejohn, 1983: 12, 37; Parkin, 1988: 681-683). Por otra parte, y a pesar también de las discrepancias teóricas existentes entre ambos clásicos de las ciencias sociales, algunos sociólogos han defendido la pertinencia de conjugar los criterios empleados por uno y otro en el tema específico de la estratificación (Lenski, 1982: 32-42); Littlejohn, 1983: 48-49). El presente trabajo se hace eco de tal conveniencia, como se pone de manifiesto al señalar los criterios utilizados para caracterizar los estratos sociales en Iberoamérica.

3 Los intentos más sistemáticos de la CEPAL por cuantificar la magnitud de los distintos estratos sociales de Iberoamérica en el periodo de referencia aparecen en dos textos: Filgueira y Carlo Geneletti, 1981; y CEPAL, 1989. Ambos dividen a la población económicamente activa en cuatro conjuntos de estratos que, si bien son en buena medida equiparables, reciben en cada uno de ellos distintas denominaciones: medios y superiores, inferior en ocupaciones secundarias, inferior en ocupaciones terciarias e inferior en ocupaciones primarias, en el primer texto; y en el segundo: no manuales, manuales en sectores secundario y terciario, trabajadores en servicios personales y manuales en el sector primario.

4 Para conocer la importancia cuantitativa de estos sectores, se debe consultar un libro PREALC, 1982 y dos revistas: Informa e Informa, América Latina y el Caribe. Panorama Laboral. 
integran tres tipos de componentes: ${ }^{5}$ estrato, sector y subsistema. La pertenencia a un estrato social se determina por la posesión y el control de los medios de producción, la magnitud de los medios de producción poseídos o controlados, la dimensión de los recursos materiales obtenidos, el nivel de cualificación del trabajo desempeñado y las condiciones de trabajo (rural o urbano, manual o no manual, etc.), pero también por el prestigio y el poder detentados. Los sectores sociales están conformados por unidades productivas similares, las cuales se componen de uno o más estratos. Para caracterizar y distinguir tales sectores, en este texto se utilizan una serie de variables. Según el ámbito en el que se desenvuelven, se dividen entre rurales, con actividades básicamente agropecuarias, y urbanas, dedicados a la industria, el comercio y los servicios. De acuerdo con su tamaño, se distinguen las unidades productivas familiares de las complejas, las empresas grandes y medianas. Según el tipo de propiedad, se dividen en privados, comunales y estatales. El nivel de la tecnología dura y suave empleada, asunto directamente vinculado con el origen temporal del sector en cuestión y que permite distinguir entre sectores tradicionales, modernos e informales, se encuentra ligado asimismo con distintos tipos de relaciones entre los componentes de las mismas unidades productivas: corporativas o individuales, autoritarias o democráticas, asalariadas o no asalariadas. Por su parte, los subsistemas aglutinan a los sectores que comparten el último conjunto de rasgos.

\section{Estratos}

Los diez estratos en que se propone dividir la estructura social prevaleciente en Iberoamérica durante la segunda mitad del siglo que

5 Anthony Giddens (1991: 305-306, 765, 771) distingue tres tipos básicos de "agrupamientos": categoría social, agrupamiento estadístico de individuos que comparten uno o varios rasgos; grupo social, conjunto de individuos que, a diferencia de los integrantes de la categoría social, interactúan de manera sistemática, se reúnen en un lugar específico y atribuyen una importancia particular a sus características comunes; y agregado: reunión de personas que comparten un mismo lugar y tiempo, pero interactuando de manera difusa y sin integrar un grupo solidario; como sucede con los pasajeros que esperan en un aeropuerto o con los espectadores de una película. De acuerdo con esta tipología, los componentes analizados en el presente texto reúnen las características adjudicadas a la categoría social, pero resulta dudoso que, todos ellos, puedan ser considerados plenamente como grupos sociales. 
está por terminar, se pueden aglutinar en tres conjuntos. ${ }^{6}$ El que domina y dirige a las naciones del área posee y controla los medios de producción más importantes $\mathrm{y}$, por tanto, concentra tanto buena parte de los recursos materiales disponibles como el prestigio y el poder económico y político. Este primer conjunto se compone de tres estratos integrados respectivamente por latifundistas, grandes y medianos empresarios capitalistas, y altos funcionarios públicos. El estrato latifundista es eminentemente rural, en el sentido de que posee o controla grandes y medianas unidades productivas agropecuarias. Sin embargo, mantiene relaciones no estrictamente modernas con sus trabajadores subordinados, al contrario de lo sucedido con los otros dos estratos de este mismo conjunto. Los empresarios capitalistas están relacionados tanto con el ámbito rural como con el urbano. Por su parte, a través de sus cargos, los altos funcionarios públicos detentan un control económico y político difícil de minusvalorar, aunque sean asalariados, no necesariamente poseen medios de producción significativos y pueden tener intereses distintos a los otros dos estratos poderosos. Si bien estos tres estratos, incluso en conjunto, representan una escuálida minoría en sus respectivas sociedades, controlan directamente las fuentes de trabajo de gran parte de la población, en concreto del conjunto de estratos que se menciona a continuación. (Este primer conjunto de clases podría identificarse grosso modo con la categoría de ocupación de "empleadores", en cualquiera de las ocupaciones, y con la ocupación de "directores y funcionarios públicos superiores").

En efecto, éste está integrado por tres estratos que comparten la dependencia de sus ocupaciones en relación con las clases anteriores: el de los arrendatarios y dos estratos asalariados, el manual u obrero y el no manual. Los arrendatarios son la contraparte de los latifundistas, a

6 Con seguridad esta división en diez estratos será vista como excesivamente prolija por algunos estudiosos, como los partidarios ya mencionados de enfoques dicotómicos, pero a otros les parecerá demasiado escueta, al no incluir a muchos grupos sociales que podrían ser catalogados como estratos. Sin embargo, la propuesta aquí expuesta se basa en la suposición de que, a partir de los criterios empleados, que fueron seleccionados de entre los más comúnmente utilizados en visiones globales como la presente, el número de estratos establecido constituye el mínimo indispensable, lo que implica que todos ellos admiten subdivisiones. 
quienes pagan una renta, preferentemente en especie o trabajo, por el usufructo de una parcela. Por tanto, este estrato, también eminentemente rural, no incluye a aquellos arrendatarios que controlan extensiones apreciables de tierra y que pagan su renta en dinero. El estrato obrero, que principalmente trabaja en actividades agropecuarias e industriales ligadas al sector privado, y el estrato asalariado no manual, ocupado de manera preponderante en el ámbito urbano, el sector público y el sector terciario de la economía, en general se distinguen entre sí, además de los aspectos mencionados, por los niveles de ingreso, la cualificación laboral, las condiciones de trabajo y el prestigio. (Este segundo conjunto de estratos podría identificarse, también grosso modo, con la categoría ocupacional de "asalariados" en cualquiera de las ocupaciones).

El tercer conjunto está compuesto por cuatro estratos, tres de los cuales "campesinos, trabajadores informales urbanos y pequeña burguesía" están integrados en lo fundamental por pequeños propietarios (en la terminología censal, incluye dos categorías ocupacionales, "trabajador por cuenta propia" y "trabajador familiar no remunerado", respecto a todas las ocupaciones, salvo a la de "directores y funcionarios públicos superiores"). Más o menos identificables con los pequeños productores agropecuarios, los campesinos, a pesar de ser propietarios de sus medios de producción, poseen escasos recursos materiales y utilizan técnicas poco productivas de origen remoto. Los trabajadores informales comparten con los campesinos la escasez de recursos materiales y la baja productividad, pero se distinguen de ellos por el origen más reciente tanto de sus propias ocupaciones como de una parte impor- tante de su tecnología, así como por su carácter eminentemente urbano. Así como estos trabajadores informales, la pequeña burguesía desempeña actividades no agropecuarias, pero a diferencia de ellos poseen un nivel significativo de recursos materiales y prestigio. El cuarto estrato de este conjunto, el de los comuneros o cooperativistas (a los que en los censos de población sólo en ocasiones se les ubica dentro de una categoría ocupacional específica, la de "miembro de cooperativa de producción"), se distingue de los nueve estratos restantes por detentar de manera autogestionada sus medios de producción. Si bien en la mayoría de los casos se ubica en el campo, está compuesto por indígenas y emplea técnicas tradicionales, también se localiza en las 
urbes, ostenta niveles notables de productividad y está integrado por otros grupos étnico-culturales.

A partir de los comentarios que acompañan a la clasificación precedente, es fácil establecer los estratos predominantes en los ámbitos rural y urbano, así como distinguir los estrictamente modernos de los tradicionales y los resultantes de los efectos indeseables de la modernidad. De los diez estratos mencionados, dos se ubican tanto en el campo como en la ciudad "empresarios capitalistas y obreros manuales", cuatro son típicamente rurales "latifundistas, arrendatarios, campesinos y comuneros" y los cuatro restantes, principalmente urbanos: altos funcionarios públicos, asalariados no manuales, pequeña burguesía y trabajadores informales. Por otra parte, latifundistas, arrendatarios, campesinos y comuneros conforman los estratos de más añeja consolidación; empresarios capitalistas, altos funcionarios públicos, obreros, asalariados no manuales y pequeña burguesía integran los estratos modernos; al tiempo que los trabajadores informales constituyen el resultado más patente de los efectos no previstos de la modernidad.

Antes de indicar la composición de los siete sectores integrantes de la estructura social iberoamericana, es conveniente subrayar el hecho de que la clasificación de estratos expuesta, como no podría ser de otra manera, es una simplificación de la realidad, pues la complejidad inherente a ésta nunca puede ser aprehendida por completo. Una clara manifestación de ello es la frecuente existencia de personas y grupos sociales que no se ajustan estrictamente a ninguno de los estratos señalados, bien por desarrollar de manera temporal pero cíclica actividades laborales propias de otro estrato, bien porque su ocupación lleva consigo características o recompensas no consideradas como típicas. ${ }^{7}$ Como es lógico, estas apreciaciones también son aplicables a las divisiones en los sectores y subsistemas analizados a continuación.

\section{Sectores}

Estos diez estratos pueden agruparse en siete sectores, cuatro eminentemente rurales "comunal, campesino, latifundista y

7 Algunas de las muchas expresiones rurales de estos problemas son expuestas en dos libros colectivos: Duncan e lan Rutledge, 1987 y Antonio García, 1981. 
capitalista" y tres principalmente urbanos: estatal, capitalista e informal. Por otra parte, el comunal, el campesino y el informal están conformados por un solo estrato, en tanto que los cuatro restantes integran varios. Los sectores comunal, campesino y latifundista, a pesar de haber incorporado de manera bastante generalizada tecnologías modernas, como el uso de fertilizantes y plaguicidas, comparten la utilización de técnicas ancestrales. Las relaciones sociales de estos tres sectores tienen asimismo un origen secular, pero no son en absoluto homogéneas. En el sector latifundista priman las relaciones de explotación no estrictamente capitalista, en donde el minifundio desempeña un papel importante. Los campesinos conforman grupos relativamente independientes, en los que sigue siendo plausible un cierto nivel de autosubsistencia. En el sector comunal también están presentes estas características, pero se distingue del anterior, y de todos los otros sectores, tanto rurales como urbanos, por su forma de organización comunitaria, tanto en lo político (las formas de gobierno local mantienen características democráticas de viejo cuño) como en lo económico, en donde sobresale la propiedad colectiva de la tierra. Estas diferencias cobran su verdadera relevancia cuando se repara en el hecho de que, de todas las unidades productivas complejas consideradas, ${ }^{8}$ las de este sector son, con diferencia, las que tienen un funcionamiento más democrático. Sin embargo, en este sector autogestionado suelen coexistir distintas modalidades de usufructo privado, lo que, entre otras cuestiones, explica las notables diferencias de ingreso perceptibles al interior de sus comunidades. Por su parte, si se distingue al sector capitalista agrícola del urbano no es bajo la suposición de que haya diferencias en cuanto al carácter capitalista de uno y otro, sino por sus apreciables disparidades en el tipo de actividades laborales, el hábitat, las condiciones de trabajo e incluso el nivel de ingreso.

8 Resulta lógico suponer que en la actualidad el subsistema tradicional se encuentre refugiado exclusivamente en el campo, pues durante por lo menos la segunda mitad del siglo $\mathrm{XX}$, las ciudades iberoamericanas, además de expandirse dramáticamente, experimentaron transformaciones cualitativas de tal envergadura que no es probable puedan detectarse en ellas grupos sociales con características ancestrales suficientemente significativas para catalogarlos como tradicionales. 
De los tres sectores urbanos los más similares son el capitalista, que incluye a la pequeña burguesía, y el estatal. En ambos, la gran mayoría de sus integrantes es asalariada, ya sean obreros o trabajadores no manuales, al tiempo que comparten el uso de tecnologías y formas de organización modernas, lo que no está reñido con el habitual carácter autoritario de estas últimas. Sin embargo, las condiciones de trabajo los distancian a menudo, así como la posición social, la ideología y los intereses de sus respectivos "directores". Desde luego, estas últimas diferencias fueron más notables durante las tres décadas, entre 1950 y 1980 aproximadamente, en las que se conjugaron el auge económico con el predominio de concepciones del sector público comprometidas con la expansión del estado de bienestar; posteriormente, tales diferencias se fueron difuminando, pero todavía siguen siendo perceptibles. Por su parte, el sector informal, conformado exclusivamente por el estrato homónimo, incluye unidades productivas muy diversas, pero que tienen en común su escaso tamaño y productividad. Por tanto, en general los ingresos de los trabajadores de este sector son también bajos, además de que no se suelen beneficiar de los logros obtenidos en la época de auge económico por los asalariados de los sectores estatal y capitalista urbano.

\section{Subsistemas}

Los siete sectores mencionados se han aglutinado en tres subsistemas: tradicional, moderno e informal, cuya coexistencia pone en evidencia el carácter heterogéneo de la estructura social iberoamericana, así como, por otra parte, de su sistema productivo. El primero es eminentemente rural, ${ }^{9}$ al contrario del tercero, exclusivamente urbano, al tiempo que el moderno se despliega en ambos hábitats. El

9 En un famoso libro, Hernando de Soto (1987) tuvo la originalidad de presentar a los trabajadores informales como empresarios innovadores y competitivos, aunque los considera parte integrante, y en esto no hace sino seguir las interpretaciones más usuales, de una estructura social dual. En la propuesta de Hernando de Soto, los dos polos de tal estructura son el mercantilismo y el liberalismo, lo que no deja también de ser novedoso frente a los planteamientos más frecuentes, que han percibido a la estructura en cuestión dividida entre lo tradicional y lo moderno o entre lo feudal y lo capitalista. Ante este panorama, la visión de Gustavo Esteva (1992: 2) resulta en verdad singular, pues concibe al llamado sector informal como "una formación social y cultural 
subsistema tradicional está integrado por tres sectores rurales "comunal, latifundista y campesino" y el subsistema informal, por un solo sector urbano, el no estructurado, pero el subsistema moderno incluye a los sectores capitalistas rural y urbano, así como al sector estatal, el cual mantiene una presencia no desdeñable en el campo, a pesar de ser principalmente urbano.

Tres cuestiones relativas al trabajo se constituyen en claves para distinguir los tres subsistemas: el papel del trabajo en la vida del trabajador, la mayor o menor diversidad de sus opciones laborales y el grado de control ejercido por el trabajador sobre su actividad laboral y el fruto de su trabajo. En las sociedades tradicionales agrarias, las actividades encaminadas a la obtención de recursos materiales, en contra de lo que comúnmente se afirma, ocupaban un tiempo relativamente reducido en la vida de las personas, pues estaban condicionadas por ciclos agrícolas estrictos. Esto se pone de manifiesto, entre otras cosas, en los abundantes días festivos de los que se disfrutaba anualmente. De manera simultánea, las opciones laborales eran escasas y no solían llevar consigo cambios importantes en el nivel de ingresos del trabajador. Además, éste obraba con cierta libertad en el proceso de producción, si bien entre los distintos sectores que componían estas sociedades agrarias existían diferencias notables en cuanto al control ejercido por el trabajador sobre el producto de su trabajo: en ocasiones era notable, en otras se veía obligado a desprenderse de buena parte de él. Cuando la pretérita sociedad agraria iberoamericana quedó inserta en una estructura social más compleja y de nuevo cuño (es decir, cuando se transformó en subsistema tradicional), algunas de esas características permanecieron, pero otras cambiaron. Por ejemplo, las opciones laborales de sus trabajadores se ampliaron al poder acceder, sobre todo a través de la emigración, a actividades propias de otros subsistemas.

Con la implantación del Estado benefactor, que desde hace algunos quinquenios tantos y tan variados embates viene recibiendo, apareció una nueva forma de trabajo: el empleo, entendido éste como el acceso generalizado a posiciones laborales que proporcionan ingresos altos $\mathrm{y}$

novedosa, que puede ser vista como embrión de porvenir: una realidad posmoderna, heraldo de libertad y autonomía". 
constantes, que es seguro y que no implica mayores preocupaciones y desafíos, pues el empleado se reduce a llevar a cabo las acciones que le son ordenadas y para las cuales ya fue previamente capacitado. Antes de ese momento tal situación no existía, por lo menos de manera masiva. Sin embargo, en las nuevas circunstancias, el empleado se queda sin control sobre su actividad laboral y el fruto de su trabajo, el cual es ejercido por los empresarios y altos funcionarios públicos; concomitantemente, se ve impelido a dedicar un tiempo dilatado a solventar unas necesidades materiales cada vez más numerosas, pero logra circunscribir su actividad laboral a tiempos limitados y disfrutar de vacaciones sin preocupaciones económicas. Teóricamente, en esta sociedad las opciones de empleo son muy variadas, pero en la práctica se reducen por el carácter especializado de los trabajos y por el miedo a perder las ventajas derivadas de permanecer en la misma empresa. Estas características laborales están presentes en el subsistema moderno iberoamericano, con la diferencia de que en éste el empleo es menos generalizado, peor retribuido y más inseguro.

En el subsistema informal, el trabajador es más autónomo, pues tiene posibilidades relativamente amplias de decidir cómo trabajar y a quién vender sus productos, pero con frecuencia necesita dedicar un tiempo prolongado a obtener bienes materiales, porque de ello suele depender el volumen de sus ingresos. En ocasiones, esto se traduce en un trabajo físico más prolongado; en otras, en calibrar opciones laborales distintas o posibilidades de mejorar su microempresa. El trabajador informal no tiene un empleo, "se busca la vida", según reza la conocida expresión popular, se las ingenia para encontrar, desde luego con desigual fortuna, los más adecuados medios de subsistencia en un mercado con opciones múltiples pero que le dificulta la acumulación de riqueza.

${ }^{10}$ Para cuantificar estas variaciones, y pese a que los resultados de tal proceder no puedan tenerse sino como una aproximación, se adjudicaron los porcentajes relativos a ciertos sectores delimitados por el PREALC (1982) a los subsistemas diferenciados en este texto. En este sentido, el subsistema moderno se identificó con el sector formal urbano, compuesto por empleadores y asalariados no agrícolas, con la excepción de los trabajadores del servicio doméstico, así como, pero sólo en el caso de los administrativos, profesionales y técnicos, por trabajadores por cuenta propia y familiares 
Por integrar unidades productivas distintas, los miembros de los diferentes subsistemas, como los de los sectores, no interactúan en las mismas instituciones laborales, pero de ello no se debe sacar la conclusión de que son mundos independientes, sin relaciones entre sí. Por el contrario, las relaciones son constantes tanto en lo económico como en lo social. En un grado notorio, actualmente los subsistemas tradicional e informal dependen económicamente del moderno, el más poderoso en este sentido, pues aquellos sectores le compran a éste insumos y bienes de consumo, al tiempo que le venden bienes y servicios de diverso tipo. Por ejemplo, el subsistema tradicional compra fertilizantes, plaguicidas y diversos bienes de consumo al subsistema moderno y le vende parte de su producción agropecuaria, para que la consuma o comercialice nacional o internacionalmente. De manera similar, el subsistema informal compra insumos y bienes de consumo al subsistema moderno y vende bienes y, sobre todo, servicios a las personas y empresas que lo componen. Pero si las relaciones económicas muestran que los vínculos entre los subsistemas tradicional e informal son más débiles que los que ambos mantienen con el subsistema moderno, en ciertos aspectos sociales y culturales eso no está tan claro, pues la relación entre los subsistemas no modernos es en ocasiones estrecha, aunque también en este sentido sus relaciones con el subsistema moderno son importantes, como en la salud y la educación.

no remunerados. El subsistema informal se identificó con el sector informal urbano, integrado por los trabajadores no agrícolas por cuenta propia y familiares no remunerados (en ambos casos excepto entre los administrativos, profesionales y técnicos), así como el servicio doméstico. Al subsistema tradicional, por último, se le adjudicaron los porcentajes del sector tradicional agrario, conformado por trabajadores agropecuarios por cuenta propia y familiares no remunerados, siempre y cuando no sean profesionales y técnicos. De los otros dos sectores establecidos por el PREALC, al sector minero, que sólo excepcionalmente ha llegado a representar $5 \%$ de la mano de obra nacional, se le excluye cuando aparece independizado; también se excluye al llamado sector moderno agrícola (configurado por el grueso de los patrones y asalariados agropecuarios), por no poderse distinguir a su interior entre el componente verdaderamente moderno y el que, según la propuesta defendida en el presente trabajo, pertenecería al sector latifundista y, por tanto, al subsistema tradicional. 


\section{Un poco de historia}

En cuanto al origen y consolidación de los tres subsistemas, el tradicional, en lo fundamental, adquirió sus características específicas durante la Colonia, pues, si bien ha incorporado en ocasiones rasgos prehispánicos, en general éstos se transformaron profundamente al adecuarse a la nueva sociedad surgida después de la Conquista. La independencia de la gran mayoría de los pueblos iberoamericanos en las primeras décadas del siglo XIX no se tradujo en transformaciones sustanciales de sus respectivas estructuras sociales. Sin embargo, algunos de los cambios ocurridos en los 50 años posteriores a la independencia anticiparían la gran transformación provocada por la implantación de la reforma liberal, que comenzó su apogeo en torno a 1870. Me refiero principalmente al fortalecimiento del poder económico y político de los terratenientes, que se manifestó, entre otras cuestiones, en un mayor control sobre la mano de obra y en la correlativa pérdida de autonomía de ciertos conjuntos de trabajadores, como los llaneros venezolanos y los gauchos argentinos (Lynch, 1988: 143-145).

Existe un notable consenso acerca de que en 1870 comenzó un nuevo periodo en la historia de Iberoamérica, pero las opiniones son muy dispares respecto a cuándo se le debe dar por concluido. El marxista Agustín Cueva (1990: 144-145), que lo denomina "modalidad oligárquico-dependiente de desarrollo del capitalismo latinoamericano", ubica el comienzo de su final a lo largo de más de 60 años, entre la revolución mexicana de 1910 y el año de 1970 en Ecuador. La Comisión Económica para América Latina y el Caribe (CEPAL) sostiene que fue en el lapso transcurrido entre las dos guerras mundiales, entre 1914 y 1950 aproximadamente, cuando se produjo un cambio en el modelo de crecimiento económico, que consistió en el tránsito de un desarrollo hacia fuera, basado en la exportación de bienes primarios, agropecuarios y mineros, a un desarrollo hacia adentro, basado en la industrialización inducida por la sustitución de importaciones (Rodríguez, 1980: 33; Sunkel y Paz, 1970: 344-361). De manera necesariamente puntual, en la magna obra sobre la historia de América Latina dirigida por Leslie Bethel (1990-1992), el periodo que ahora nos ocupa se encuentra delimitado por las fechas de $1870 \mathrm{y}$ 1930. Por mi parte, considero oportuno que, de acuerdo con la dinámica socioeconómica de Iberoamérica, el final del susodicho 
periodo se extienda, de manera aproximada, desde los inicios hasta la mitad del siglo XX, pues es a lo largo de estos años cuando las sociedades iberoamericanas comienzan, sucesivamente, procesos relativamente sostenidos e intensos de industrialización y urbanización, aspectos claves para diferenciar al periodo más reciente de la historia de la región del que le precedió.

En efecto, alrededor de 1900, la población que residía en ciudades con más de 20000 habitantes no alcanzaba a representar el 10\% de la nacional en ninguno de los países de la región salvo en cuatro Argentina, Uruguay, Chile y Cuba, en los que oscilaba entre 20 y $30 \%$ (Sánchez-Albornoz, 1994: 152-153). Cinco décadas más tarde, a mediados del siglo XX, dicho porcentaje sólo era inferior al $10 \%$ en Honduras; en nueve países Paraguay, Bolivia, Perú, Ecuador, Costa Rica, Nicaragua, El Salvador, Guatemala y República Dominicana se situaba entre 10 y 20\%; en otros cuatro: Brasil, Colombia, Panamá y México oscilaba entre 20 y 30\%; en dos más: Cuba y Venezuela, se ubicaba en torno a 35\%; y en los tres restantes -Argentina, Uruguay y Chile- había ascendido entre 48 y 65\%. Al comenzar 1980, en ningún país iberoamericano la proporción de habitantes en ciudades de más de 20000 habitantes era inferior a los 20 puntos; en siete Paraguay, Bolivia, Costa Rica, Nicaragua, Honduras, El Salvador y Guatemala oscilaba entre 20 y $35 \%$; en ocho más: Brasil, Perú, Ecuador, Colombia, Panamá, México, República Dominicana y Cuba entre 40 y $55 \%$; y en los cuatro restantes -Argentina, Uruguay, Chile y Venezuela- se situaba en torno a 70\% (CEPAL, 1991: 7). De forma similar, la población económicamente activa (PEA) urbana, la ocupada en los sectores secundario y terciario, ascendió notablemente entre 1950 y 1980. En la primera de estas fechas sólo representaba un porcentaje claramente superior a 40 puntos en cinco repúblicas: Argentina (72\%), Uruguay (78\%), Chile (63\%), Venezuela (51\%) y Panamá (47\%); pero en 1980 en ninguna era inferior al 40\% y en nueve era superior al 60\%: Argentina (84\%), Uruguay (82\%), Chile (74\%), Venezuela (79\%), Brasil (62\%), Colombia (65\%), Panamá (66\%), Costa Rica (65\%) y México (62\%) (PREALC, 1982).

Sin embargo, el periodo transcurrido entre 1870 y la primera mitad del siglo XX, no sólo se caracterizó porque en él se inició el proceso de urbanización que habría de consolidarse en el periodo siguiente, lo cual condujo a su vez al fortalecimiento de los sectores estatal y capitalista urbano. También se caracterizó por transformaciones notables en 
todos los ámbitos de la realidad, incluido, por supuesto, el político. Entre ellas, no deben soslayarse algunas referidas al campo socioeconómico que ahora nos ocupa. El sector latifundista se robusteció sobremanera, generando efectos contrapuestos. En lo económico, esto potenció la acumulación de capital y el crecimiento que servirían de fundamento al desarrollo posterior. En lo social, sus consecuencias fueron predominante- mente negativas, al margen de que en ciertos casos diese lugar al nacimiento del sector capitalista rural.

La expansión del sector latifundista supuso, además, un ataque frontal al sector comunal, al embestir contra sus dos pilares principales, la propiedad colectiva de la tierra y el sistema de autogobierno local. Los terratenientes consiguieron así un doble propósito: aumentar las extensiones de sus tierras y obligar a los ex comuneros a que trabajaran para ellos. Pero no fue ésta la única forma empleada para obtener mano de obra forzada. A tal mecanismo se sumaron otros, como los derivados de la puesta en práctica de las leyes contra la "vagancia". Si los terratenientes necesitaron de este tipo de coerciones para conseguir trabajadores fue porque las condiciones laborales que impusieron en sus propiedades fueron draconianas, según se pone de relieve en los ingresos bajos, en las largas jornadas de trabajo, en las autoritarias relaciones establecidas al interior de las unidades productivas de este sector y en un generalizado sistema de crédito, impuesto por los propios latifundistas, con intereses desmedidos y cuyas deudas se transmitían de generación en generación. Como es lógico, el resultado de todo ello fue el notorio incremento de la pobreza y la explotación en el campo iberoamericano (Cueva, 1990: 134-141; Favre, 1998: 32-35). Por tales razones, lo acontecido en este periodo tiene una singular relevancia para explicar las importancias relativas que tienen en la actualidad los distintos sectores sociales del subsistema tradicional.

\section{Magnitud actual de los subsistemas}

Las cifras relativas a la evolución de la urbanización y de la PEA no agrícola a lo largo del siglo XX, sirvieron para demostrar que en la segunda mitad de esta centuria se consolidó la estructura social imperante en la Iberoamérica actual, al generalizarse intensos incrementos de la población urbana y de la ocupación no agrícola, los cuales han tenido como trasfondo la progresiva importancia de la producción industrial y la ampliación del sector público, debido a la 
implantación, aunque sea parcial, del Estado benefactor, con una progresiva incidencia, por lo menos hasta 1970, en la economía y el bienestar social nacionales. Veamos a continuación cómo evolucionaron los subsistemas durante el medio siglo mencionado. En efecto, aunque el modelo de estructura social esbozado en los primeros apartados se considera válido para, por lo menos, la segunda mitad del siglo XX, ello no significa que las sociedades iberoamericanas hayan permanecido sin experimentar cambios profundos a lo largo de tales décadas. Por el contrario, en este periodo han tenido lugar transformaciones importantes, como lo muestran, por ejemplo, las propias variaciones cuantitativas de los tres subsistemas establecidos en este trabajo.

De acuerdo con la importancia relativa de cada subsistema en 1950, se pueden distinguir tres tipos de países en Iberoamérica. El primero estaba conformado por Argentina, Uruguay y, con ciertas reservas, Chile, los únicos que entonces podían catalogarse como predominantemente modernos. En los tres, el subsistema tradicional representaba menos de $10 \%$ de la fuerza laboral, pero mientras en Argentina y Uruguay el subsistema moderno era claramente mayoritario y varias veces superior al informal, en Chile el subsistema moderno no alcanzaría a englobar a la mitad de la PEA nacional ni duplicaría a un subsistema informal que, por otra parte, parece demasiado abultado para esa fecha. El segundo grupo de países estaba compuesto por Brasil, Venezuela, Panamá, Costa Rica, y se caracterizaba por una magnitud intermedia del subsistema moderno (entre 29 y $35 \%$ ) y porque éste duplicaba al informal. Sin embargo, en estos países el tamaño del subsistema tradicional era dispar: en Venezuela y Costa Rica era de nivel intermedio (20 y 23\% respectivamente), pero en Brasil y Panamá era elevado (38 y 47\%). En los otros 11 países de la región, el subsistema moderno, además de no alcanzar a duplicar al informal, oscilaba entre 9 y $24 \%$, en tanto que el tradicional representaba entre 33 y $58 \%$, salvo en Nicaragua, donde era algo inferior.

En las décadas posteriores a 1950, hubo cambios significativos en la importancia relativa de los subsistemas. Las tendencias generales al respecto fueron las siguientes: incremento notable del subsistema moderno salvo en Argentina y Uruguay, los países que lo tenían más abultado inicialmente e informal con la única excepción de Chile, lo que refuerza la sospecha de que la estimación de su tamaño en 1950 es 
exagerada, así como la correlativa y también notoria disminución del subsistema tradicional, salvo en los países en los que ya era muy reducido a mediados del siglo. En efecto, entre 1950 y 1990, los subsistemas moderno e informal aumentaron sus importancias relativas, de la misma forma que la población urbana en su conjunto, al tiempo que descendía la del subsistema tradicional, como sucedió también con la población rural. A lo largo de estos 40 años, y en relación con la PEA total iberoamericana, el subsistema moderno empleado en actividades no agrícolas pasó de 30 a 51\%, el subsistema informal ascendió de 13 a 23\% y el subsistema tradicional descendió de 33 a menos de $20 \%$.

Debido a estas transformaciones en la estructura social iberoamericana que lógicamente se presentaron con diferente intensidad entre los países de la región, en 1990 la situación era distinta a la de 40 años atrás. Al finalizar el siglo XX, el número de repúblicas con una estructura social mayoritariamente moderna se elevó a siete: Argentina, Uruguay, Chile, Brasil, Venezuela, Panamá y Costa Rica. En estos países, la mano de obra empleada en el subsistema moderno representa cuanto menos a la mitad de la PEA nacional correspondiente y duplica a la ocupada en el informal. Sin embargo, el subsistema tradicional se sitúa en torno a 5\% en Argentina, Uruguay y Chile, a $10 \%$ en Venezuela y Costa Rica, y a 20\% en Brasil y Panamá. En el mismo año de 1990, los países en los que predominaban las estructuras sociales no estrictamente modernas eran Bolivia, Perú, Ecuador, Paraguay, Nicaragua, Honduras, El Salvador y Guatemala. En estos ocho países, el subsistema moderno oscilaba entre 28 y $39 \%$, salvo en Ecuador donde era más alto. No obstante, en todos ellos la suma de los porcentajes de los subsistemas informal y tradicional era superior al del moderno. Aunque en este grupo, como en el anterior, el subsistema moderno era más voluminoso que el informal, distaba mucho de duplicarlo. Por su parte, el subsistema tradicional seguía teniendo una importancia notable en este grupo, pues en general oscilaba entre 19 y $29 \%$ de la PEA nacional, porcentaje que incluso era mayor en Bolivia y probablemente en Paraguay. En una posición intermedia entre los dos grupos anteriores se encontraban Colombia, México y República Dominicana. El subsistema moderno de estas tres naciones oscilaba entre 46 y $50 \%$ "es decir, no representaba la mayoría de la PEA nacional en ninguno de ellos", pero era superior, y en esto se 
distingue de los integrantes del grupo anterior, a la suma de los subsistemas informal y tradicional.

Antes de dar por concluido este texto, quisiera mencionar, aunque sea brevemente, cuál es en la actualidad la posición mundial de Iberoamérica, a partir de la importancia que cada uno de los subsistemas tienen en distintas regiones del planeta. Como en tantos otros aspectos, la posición intermedia de Iberoamérica en el contexto mundial (Bulmer-Thomas, 1998: 13; y Lizcano Fernández, en prensa b, en especial, el primer capítulo) queda en evidencia al constatar las importancias relativas de los tres subsistemas. En los países desarrollados, la estructura social es hasta tal punto diferente a la de Iberoamérica que probablemente no les sea aplicable la división en tres subsistemas, pues en esos países el predominio de lo moderno es casi total, dada la virtual inexistencia de grupos sociales que en verdad merezcan el apelativo de tradicionales y la relativamente escasa magnitud de un sector informal que, además, presenta diferencias notables con el del Tercer Mundo. Estas sociedades se distinguirían así claramente de las del resto del planeta por la homogeneidad de su estructura social, que contrasta con la heterogeneidad de las estructuras sociales características del Sur, donde los tres subsistemas son relevantes. Esta diferencia entre el Norte y el Sur, así como la posición intermedia de Iberoamérica al respecto, se pone en evidencia al comparar algunos porcentajes referidos a la década de los ochenta, como son el del empleo asalariado no agrícola o urbano (que de manera aproximada representa al subsistema moderno e indirectamente a su contraparte urbana, el subsistema informal) respecto a la población económicamente activa (PEA) no agrícola total, y el del empleo agrícola no asalariado en relación con la PEA total agrícola, que también de forma aproximada se le puede identificar con el subsistema tradicional.

Pues bien, en los países desarrollados el empleo urbano asalariado suele situarse por encima del $90 \%$, en un contexto en el que la PEA agrícola no alcanza el 10\%. En contraste, en Iberoamérica, con una PEA urbana promedio de $75 \%$, la población asalariada no agrícola oscila entre 50 y $80 \%$, en tanto que la PEA rural no asalariada se sitúa entre 40 y 70\%. Pero estos porcentajes sobre Iberoamérica no sólo difieren de los de los países desarrollados sino también de los prevalecientes en otras regiones del Sur en las que el subsistema moderno es más reducido y el tradicional, más numeroso. Por ejemplo, 
en los países en vías de desarrollo con economías de mercado de Asia meridional y oriental, dentro de la PEA agrícola, que en promedio supera el 60\%, el empleo no asalariado fluctúa entre 50 y $90 \%$. Por tanto, aunque en esta región el porcentaje del empleo asalariado sobre la PEA urbana sea similar al de Iberoamérica (entre 40 y 80\%), en relación con la PEA total su subsistema moderno es menos abultado y el tradicional mucho mayor. Las diferencias entre Iberoamérica y el África subsahariana son todavía más pronunciadas, pues en esta región el empleo no asalariado suele rebasar el $90 \%$ de una PEA agrícola que representa dos tercios del total, mientras que el empleo asalariado urbano oscila entre 30 y $90 \%$.

Apartado Postal 2-29 C.P. 50000. Toluca, Estado de México.

\section{Bibliografía}

Bethel, Leslie (ed.) (1990-1992), Historia de América Latina, 10 vols. (quedan por publicarse seis más), Barcelona: Crítica.

Bulmer-Thomas, Víctor (1998), La historia económica de América Latina desde la independencia, México: FCE.

CEPAL. Comisión Económica para América Latina y el Caribe (1989), Transformación ocupacional y crisis social en América Latina, Santiago de Chile: CEPAL.

CEPAL (1991), Anuario estadístico de América Latina y el Caribe 1990, Santiago de Chile: CEPAL.

Cueva, Agustín (1990), El desarrollo del capitalismo en América Latina, 13ª . ed. aum., México: Siglo XXI.

Duncan, Kenneth e lan Rutledge (comps.) (1987), La tierra y la mano de obra en América Latina, México: FCE. (1994), El Trabajo en el Mundo 1994, núm. 7, Ginebra: OIT.

11 Los datos fueron tomados de dos textos: PNUD, 1993 (el cual ofrece porcentajes nacionales y regionales de la PEA agrícola y no agrícola en relación con la PEA total); y El Trabajo en el Mundo 1994, 1994. Esta revista presenta porcentajes nacionales (según parece, los regionales no han sido elaborados) del empleo asalariado en relación con la PEA agrícola y no agrícola. Dado que las cifras presentadas al respecto son incompletas, sobre todo las referidas a África, la información recuperada en este artículo sobre estos tópicos debe tomarse con reservas, aunque las diferencias entre las distintas regiones consideradas son tan notorias que no parece probable que el conocimiento completo de estos datos exigiese cambios sustanciales a la interpretación presentada. 
Esteva, Gustavo (1992), "Los marginales como cultura”, en Opciones (suplemento encartado en el periódico El Nacional), núm. 8, México.

Favre, Henri (1998), El indigenismo, México: FCE.

Filgueira, Carlos y Carlo Geneletti (1981), Estratificación y movilidad ocupacional en América Latina, Santiago de Chile: CEPAL.

García, Antonio (comp.) (1981), Desarrollo agrario y la América Latina, México: FCE.

Giddens, Anthony (1991), Sociología, Madrid: Alianza. (s/f), Informa, varios números, Santiago de Chile: PREALC.

OIT. (s/f), Informa, América Latina y el Caribe, Panorama Laboral, varios números, Lima:

Lenski, Gerhard (1982), "Antecedentes sobre la desigualdad social y su origen", en La desigualdad social, vol. 1, México: SEPSetentas/Diana.

Littlejohn, James (1983), La estratificación social, 2ª . ed., Madrid: Alianza.

Lizcano Fernández, Francisco (1998), "Hacia una percepción del desarrollo iberoamericano", en Cuadernos Americanos, núm. 68, México.

(s/f),"Heterogeneidad socioeconómica y étnico-cultural de Iberoamérica en la segunda mitad del siglo XX", en Historia contemporánea de América Latina, tomo V, México: UNAM.

Lynch, John (1988), “La formación de los estados nuevos”, en Manuel Lucena Salmoral, Historia de Iberoamérica, tomo III, Historia contemporánea, Madrid: Cátedra.

Parkin, Frank (1988), "Estratificación social” , en Historia del análisis sociológico, Buenos Aires: Amorrortu.

PNUD. Programa de las Naciones Unidas para el Desarrollo (1993), Informe sobre desarrollo humano 1993, Madrid: PNUD/CIDEAL.

PREALC. Programa Regional del Empleo para América Latina y el Caribe (1982), Mercado de trabajo en cifras, 1950-1980, Santiago de Chile: PREALC.

Rodríguez, Octavio (1980), La teoría del subdesarrollo de la CEPAL, México: Siglo XXI.

Sánchez-Albornoz, Nicolás (1994), La población de América Latina desde los tiempos precolombinos al año 2025, 2a . ed. corr., Madrid: Alianza.

Soto, Hernando de (1987), El otro sendero, México: Diana.

Sunkel, Osvaldo y Pedro Paz (1970), El subdesarrollo latinoamericano y la teoría del desarrollo, México: Siglo XXI. 